\title{
Multiple groups confirmatory factor analysis of the motivational factors affecting individuals' decisions about participating in action sports and an inquiry into participant action sports participatory fandom
}

\author{
S. Roger Park* \\ Department of Sport \& P.E. \\ Gonzaga University \\ 502 E. Boone Ave. \\ Spokane, WA, USA \\ E-mail: park@gonzaga.edu \\ *Corresponding author

\section{Soonhwan Lee} \\ Department of Human Performance \\ Minnesota State University \\ 1400 Highland Center \\ Mankato, MN 56001, USA \\ Fax: (570) 674-6206 \\ E-mail: soonhwan.lee@mnsu.edu
}

\begin{abstract}
The purpose of this current study was to examine if the Participant Motivations Questionnaire (PMQ) (Gill et al., 1983) was still valid for action sports participants. This study also examined factorial invariance of motivational factors of action sports participation across genders. In other words, the study wanted to test the motivational factors of action sports participation assumed to underlie the motivational factors independently for the male and female college students. Based on the results of Confirmatory Factor Analysis (CFA), the PMQ motivational factors of action sports participation do fit both male and female college students. The results of the multiple t-tests showed that female college action sports participants had higher motivation levels for achievement $(\mathrm{p}<0.001)$, miscellaneous reasons $(\mathrm{p}<0.01)$, skills development $(\mathrm{p}<0.01)$, friendships $(\mathrm{p}<0.01)$ and fun $(\mathrm{p}<0.01)$.
\end{abstract}

Keywords: action sports; action sports participatory fandom; participant motivations; multiple group confirmatory factor analysis.

Reference to this paper should be made as follows: Park, S.R. and Lee, S. (2008) 'Multiple groups confirmatory factor analysis of the motivational factors affecting individuals' decisions about participating in action sports and an inquiry into participant action sports participatory fandom', Int. J. Sport Management and Marketing, Vol. 3, No. 4, pp.348-357.

Biographical notes: Dr. S. Roger Park is currently an Assistant Professor in the Department of Sport \& P.E. at Gonzaga University. He has published articles in Sport Marketing Quarterly, International Journal of Sport Management, ICHPER-SD Journal of Research, International Journal of Eastern Sports and Physical Education and Korea Sport Business Journal. 
He also presented at the various conferences of NASSM, SMAANZ, SMA, EASM and TASSM. His research interests are sport sponsorship and cross-cultural study in sport.

Dr. Soonhwan Lee is Assistant Professor in the Department of Business at College Misericordia, Dallas, Pennsylvania. He has published in such journals as International Journal of Sport Management, NIRSA Journal, International Sports Journal, The Sport Journal, and others. His research interests are sport consumers, consumer loyalty, action sports, sport volunteerism and risk management.

\section{Introduction}

Participation in action sports has increased tremendously over the past few years (DesMarteau, 2004; Petrecca, 2000; Yin, 2001). It has been estimated that almost 100 million people participated in aggressive inline skating, white-water canoeing and kayaking, skateboarding, mountain biking, snowboarding, snowmobiling, BMX biking, wakeboarding, surfing, rock climbing, artificial wall climbing and adventure racing in 2001 (Kaufman, 2001). A 10-year study of trends in youth (ages 7 to 17) participation in sports showed an especially interesting pattern. Several traditional activities suffered large declines in participation from 1992 to 2002 : volleyball $(-48.3 \%)$, tennis $(-36.7 \%)$, bicycle riding $(-24.2 \%)$ and softball $(-29 \%)$. During the same period, three new sports exploded in popularity: snowboarding $(355.5 \%)$, inline skating $(93.9 \%)$ and skateboarding $(75 \%)$. Snowboarding skyrocketed to seven million participants in 2000 , increasing $51 \%$ between 1999 and 2000 . Snowboarding's participation has increased by $238 \%$ since 1987 ; skateboarding has increased by $49 \%$, or to 12 million enthusiasts - far outpacing tackle football, which grew by only $15 \%$, or to six million players in 2000 (Sports Participation Trends, 2003).

A similar study, completed for the same period, supports these sports participation trends (Participation Rates Slide, 2000). Out of 17 team sports, only the baseball participation rate increased $(2 \%)$, while participation in the remaining 16 team sports decreased. More specifically, the participation rate for field hockey showed the largest decline $(-25.2 \%)$, followed by ice hockey $(-18.2 \%)$, fast-pitch softball $(-13.2 \%)$, lacrosse $(-11.2 \%)$ and hard surface/grass volleyball $(-10.4 \%)$.

\section{Rationale of the study}

Very few studies have been conducted to identify the motivational factors affecting individuals' decisions about participating in action sports. Moreover, sport scholars have focused only on the traditional extreme sports such as hang-gliding, kayaking and rock climbing (Doka et al., 1990; Shoham et al., 1998) and excluded action sports such as inline skating and/or skateboarding. 


\section{Purpose of the study}

The purpose of this current study was to examine if the Participant Motivations Questionnaire (PMQ) (Gill et al., 1983) was still valid for action sports participants. This study also examined factorial invariance of motivational factors of action sports participation across genders. In other words, the study wanted to test the motivational factors of action sports participation assumed to underlie the motivational factors independently for the male and female college students.

\section{Research questions}

There were two research questions:

1 Is PMQ valid for action sports participants?

2 Are there any differences between the motivational factors affecting individuals' decisions about participating in action sports?

The first research question was answered in Part 1 and the second one in Part 2. The sampling method, data collection procedure, subjects and instrument were the same in Part 1 and Part 2 and so are described only in Part 1.

\section{Part 1}

\subsection{Literature review}

Gill et al. (1983) also tried to measure motivation for sports participation in youth. The initial study showed that the most important reasons for participating were to improve skills, have fun, learn new skills, be challenged and be physically fit (Gill, 2000). Several others used this measure, or a modification, with other youth sports samples (Gould et al., 1985; Klint and Weiss, 1986; Passer, 1988; Wankel and Kreisel, 1985), and the results are consistent in several ways. Weiss and Chaumeton (1992) cited three common threads. First, several factor analyses yielded consistent factors, including competence, fitness, affiliation, team aspects, competition and fun. Second, children and adolescents typically indicated that several motives were important. Third, there was minimal age, gender, experience or sports activity differences.

Others have used the PMQ with college-age samples. Dwyer (1992) sampled university students using a five-point response format to examine the measure's internal structure. His resulting six-factor structure (team orientation, achievement/status, fitness, friendship, skills development and fun/excitement/challenge) was similar to the results with youth samples, and all subscales were internally consistent. The most important motives that Dwyer (1992) found for participating were to:

- maintain fitness

- experience fun, excitement and challenges

- acquire and improve skills. 
These findings are consistent with the youth literature (Gill et al., 1983; Gould et al., 1985; Klint and Weiss, 1987). The least important reasons for college-age students were friendship, achievement/status and team factors; these do vary from the results with youth.

\section{Invariance testing for multiple groups}

Invariance testing for multiple groups is similar to cross-validation, in which parameter estimates, such as factor loadings, regression coefficients, etc., obtained from one group are literally forced onto the data for the other group. If the two groups are basically similar, this imposition of parameter estimates from one group will fit the data of the second group. In invariance testing, a model fit is assessed in terms of the ability of these parameter estimates from one group to reproduce the correlations of the other group.

\subsection{Methods}

\subsubsection{Sample}

One hundred and twenty college students $(52.5 \%$ female and $47.5 \%$ male; mean age $=21.79$ years, $\mathrm{SD}=4.53$ years) in a northeastern college of the USA responded to the questionnaires. The participants' educational levels ranged from graduate student $(1.7 \%)$, to freshman $(9.2 \%)$, sophomore $(14.2 \%)$, junior $(23.3 \%)$, senior $(50 \%)$ and other $(1.6 \%)$. Nineteen-point-two percent of the participants enjoyed inline skating, followed by BMX biking (12.5\%), skateboarding (5.0\%), other (26.7\%) and no response $(36.6 \%)$. The participants' average number of days for participating in inline skating and skateboarding per year was less than five days (54.2\%), 5-10 days (10.8\%), 10-20 days $(10.0 \%), 20-30$ days $(7.5 \%), 30-50$ days $(2.5 \%)$, more than 50 days $(14.2 \%)$ and no response $(0.8 \%)$. The participant's skill levels for inline skating and skateboarding were beginner $(50.8 \%)$, intermediate $(20.8 \%)$, high level $(11.7 \%)$, professional level $(0.8 \%)$ and no response $(15.9 \%)$.

\subsubsection{Instrumentation}

Participant Motivations Questionnaire (PMQ) (Gill et al., 1983) was used as the research instrument. The 30-item instrument was rated on a five-point Likert scale ranging from 1 (strongly disagree) to 5 (strongly agree). The research instrument consisted of eight dimensions, namely achievement/status with six items, team-oriented reasons with three items, fitness-oriented reasons with three items, energy release with five items, miscellaneous reasons with three items, skills development with three items, friendships with four items and fun with four items. The item responses were summed up within each sub-dimension to create eight dimensions. The reliabilities of the dimensions were $0.95,0.94,0.97,0.95,0.84,0.94,0.93$ and 0.95 , respectively. The reliability of all eight dimensions was 0.98 . The validity of this instrument was reconfirmed for the current sample.

A demographic questionnaire was developed for this pilot study to obtain information concerning gender, age, educational level, average number of days of participation in action sports, skill level and the most favourable action sports to enjoy. 


\subsubsection{Procedures}

College students in sport management classes were informed about the general purpose of the study and the survey questionnaires were distributed during the sport management classes in a northeastern college of the USA. Afterwards, the participants completed the $\mathrm{PMQ}$ and the demographic questionnaires during sport management classes.

\subsubsection{Data analysis}

A Confirmatory Factor Analysis (CFA) was used to conduct the equivalence of the PMQ model among male and female college students in a northeastern college of the USA. Based on the results of Levene's tests for equality of variances, all the motivations of participation in action sports, including achievement, team-oriented reasons, fitness-oriented reasons, energy release, miscellaneous reasons, skills development and friendships, were significant. Therefore, $t$-values, where equal variances were not assumed, were used. The assumption of normal distribution was confirmed by the skewness and kurtosis. In other words, skewness and kurtosis were located between -1 and 1 and between -1 and 2 , respectively.

In order to conduct the multiple groups CFA for the male and female college students, a series of maximum likelihood CFAs were used in the analysis of data. These CFAs were based on the AMOS 4.0 statistical program (Kim, 2002). The major consideration in conducting the equivalence of structural equation modelling was the issue of what indexes should be used to assess the overall model fit. The recommendations of $\mathrm{Hu}$ and Bentler (1999) provide some measures of model fit. First, the Chi-square goodness-of-fit statistic measures the difference between the sample covariance matrix and the covariance matrix based on the model. Statistically significant values of the $\chi 2$ indicate a poorly fitting model. Second, cut-off values of 0.95 and above should be used to support adequate fit based on the normed fit index (NFI), Tucker-Lewis index (TLI) and comparative fit index (CFI).

\subsection{Results}

Based on the results of CFA using AMOS software (see Figure 1), and the PMQ, motivational factors of action sports participation do fit both male and female college students. However, the factor loadings are not equivalent across genders. According to AMOS results of the baseline model, the Chi-squared $(\chi 2)$ goodness-of-fit was 81.05, $\mathrm{p}<0.05$; the TLI was 0.97 ; the NFI was 0.98; and the CFI was 0.98. Based on these four indexes of assessing fit in path, the PMQ baseline model fit the data. In other words, the one-factor model for male students was interpreted as marginally adequate.

Multiple-group CFA was used to determine the equivalence of the PMQ for male and female college students in a northeastern college of the USA (see Table 1). The one-factor model seems to fit the female college students $(\chi 2=48.37, p<0.05$; $\mathrm{NFI}=0.97 ; \mathrm{TLI}=0.97$; and CFI $=0.98$ ). In other words, the one-factor model for male students was interpreted as marginally adequate. The standardised factor loading estimates between indicators ranged from 0.86 to 0.98 , which were statistically significant. Moreover, the latent variable, represented by PMQ for female students, explained the most variance for achievement/status $(\mathrm{R} 2=0.95)$, followed by 
team orientation $(\mathrm{R} 2=0.90)$, fitness reasons $(\mathrm{R} 2=0.91)$, energy release $(\mathrm{R} 2=0.96)$, miscellaneous reasons $(\mathrm{R} 2=0.74)$, skills development $(\mathrm{R} 2=0.89)$, friendship $(\mathrm{R} 2=0.98)$ and fun $(\mathrm{R} 2=0.94)$.

The one-factor model also seemed to fit the male college students $\left(\chi^{2}=64.81\right.$, $\mathrm{p}<0.05 ; \mathrm{NFI}=0.97 ; \mathrm{TLI}=0.96$; and $\mathrm{CFI}=0.98$ ). In other words, the one-factor model for males was also interpreted as marginally adequate. The standardised factor loading estimates between indicators ranged from 0.76 to 0.98 , which were statistically significant. Results for male and female student factor loadings were summarised in Table 2.

Figure 1 Participation Motivation Questionnaire (PMQ) model

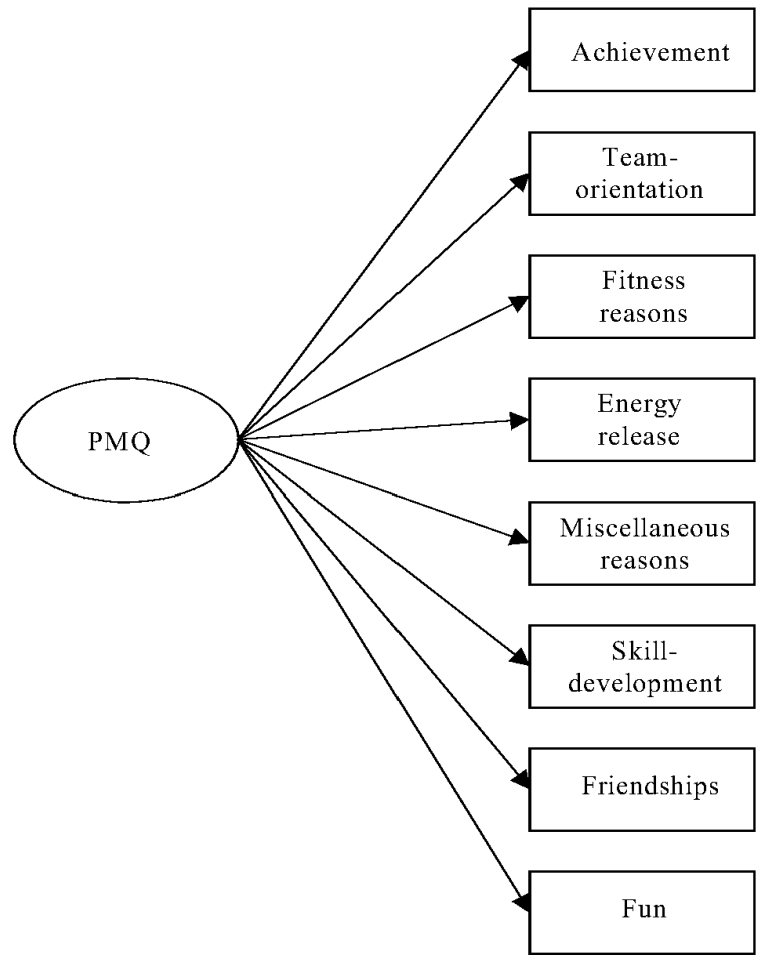

Table 1 Multiple groups confirmatory factor analysis across genders $(\mathrm{N}=120)$

\begin{tabular}{lcccc}
\hline Invariant & $\chi^{2}$ & TLI & NFI & CFI \\
\hline One-factor model (male/female) & $64.81 / 48.37$ & $0.96 / 0.97$ & $0.97 / 0.97$ & $0.98 / 0.98$ \\
\hline
\end{tabular}


Table 2 Factor loading of participant motivations questionnaire for the one-factor model for male and female college students $(\mathrm{N}=120)$

\begin{tabular}{lcc}
\hline & \multicolumn{2}{c}{ Factor loading } \\
\cline { 2 - 3 } Indicator & Male & Female \\
\hline Achievement/status & 0.94 & 0.98 \\
Team orientation & 0.76 & 0.95 \\
Fitness reason & 0.88 & 0.95 \\
Energy release & 0.88 & 0.98 \\
Miscellaneous reason & 0.86 & 0.86 \\
Skills development & 0.87 & 0.94 \\
Friendship & 0.98 & 0.99 \\
Fun & 0.90 & 0.97 \\
\hline
\end{tabular}

Note: All the factor loading estimates were statistically significant at the 0.05 level

Moreover, the latent variable (PMQ) for males explained the most variance for achievement/status $(\mathrm{R} 2=0.88)$, followed by team orientation $(\mathrm{R} 2=0.58)$, fitness reasons $(\mathrm{R} 2=0.78)$, energy release $(\mathrm{R} 2=0.77)$, miscellaneous reasons $(\mathrm{R} 2=0.75)$, skills development $(\mathrm{R} 2=0.77)$, friendship $(\mathrm{R} 2=0.96)$ and fun $(\mathrm{R} 2=0.81)$.

\section{Part 2}

\subsection{Review of literature}

Intrinsic and extrinsic motivation theory associated with sports participation has been of interest to sports psychologists and sociologists. According to Deci and Ryan (1985), intrinsic motivation explains that people participate in the sporting activity for pleasure and satisfaction. In contrast, extrinsic motivations are those that provide external rewards or negative consequences associated with nonparticipation. Lepper and Hodell (1989) identified the interactive nature of the relationship between intrinsic and extrinsic motivation.

Deci and Ryan (1985) contended that only self-determined behaviour increased intrinsic motivation, while controlled behaviour decreased this motivation. Vlachopoulos et al. (2000) identified conceptual subgroups of sports participants who may differ in their configuration of motives for participation and also examined how these motivation profiles relate to positive and negative consequences. They found a direct influence of self-determination on consequences through its propensity to facilitate enhanced psychological functioning.

Recours et al. (2004) postulated four different motivational factors of sports participation. They used four factors: competition, exhibitionism, sociability and playing to the limit, which had been previously validated in the literature. The motivation factors of competition and exhibitionism represent the extrinsic/instrumental values of modernity, while the other two factors represent the intrinsic/aesthetic values of post-modernity (Maffesoli, 1995). They found that females were much more likely to be motivated by sociability than males, and extrinsic/instrumental motives (competition/exhibitionism) were far less important as sports motivations for women than they were for men. Their results also showed that competition/exhibitionism was the only motive that changed with age. 
The research findings showed that studies in the laboratory (Butler, 1989; Deci et al., 1981; Vallerand et al., 1986) are similar to studies in sports field settings. In other words, they identified that female athletes demonstrated more intrinsic motivation and more identified regulation than male athletes, while displaying less external regulation and less motivation than men.

The aforementioned literature implies that gender can be an important social factor that significantly affects sporting activity participation. Female athletes are more likely to be intrinsically motivated regarding sporting activity than the male counterparts, although the supporting theories vary from scholar to scholar. In action sports, it is assumed that the motivation of competition or exhibitionism, which includes showing off self-taught skills/tricks and gaining public attention, will be the most important factor.

A pilot study has been conducted as a preliminary investigation about the differences in action sports fandom between Korean and American college students. The specific reason for this pilot study was to identify differences in action sports fandom levels based on nationality or different cultural background.

\section{Data analysis}

Multiple t-tests were conducted to examine differences in the motivational factors that influence individual decisions about participating in action sports between male and female college students. Hierarchical multiple linear regression analysis was also executed to investigate if action sports related to viewing preferences, achievement motives, action sports familiarity and action sports advancement. These tests explain a significant proportion of the variance for action sports participant fandom among college students.

\subsection{Results}

The multiple t-tests were conducted, and might increase type I error. Therefore, 0.01 of alpha level was applied to all the t-tests and ANOVAs. The results of the t-tests showed that female college students had higher motivation levels for achievement $(p<0.001)$, miscellaneous reasons $(\mathrm{p}<0.01)$, skills development $(\mathrm{p}<0.01)$, friendships $(\mathrm{p}<0.01)$ and fun $(\mathrm{p}<0.01)$.

Multiple ANOVAs have been conducted to identify if there were any statistical differences across education levels on participant motivational factors. Based on ANOVAs, only one motivational factor of team-oriented reasons was significantly different by educational levels. In addition, a post hoc test of Bonferroni was done to find the differences by each educational level. However, this test showed no significant differences.

\section{Discussion}

The purpose of this study was to independently test the measurement model of the PMQ assumed to underlie the participant motivational factors by male and female college students. In addition, this study also wanted to examine whether or not PMQ was valid for action sports participants. Based on the results of the CFA, the one-factor model does fit both male and female college students. However, the factor loadings are not equivalent 
across the two groups. In summary, it is noted that the 30-item PMQ for action sports participants is unequally valid for the current subjects of male and female college students.

In addition, as explained above, demographic variables such as age, educational level and skill level are the significant factors in explaining the action sports fandom of the college students. It was interesting to see that both motivation of achievement and skill level were significant factors explaining action sports participant fandom. Specifically, motivational factors that led college students to participate in action sports were significantly different across genders, educational levels and skill levels. These results indicate that action sports marketers should use different marketing strategies to provide personal-fit satisfaction for various action sports participants. Also, as the results indicated, this study confirmed unequally the validity of PMQ for demographics. Within regard to demographics, this study supported the idea that each gender had different types of motivation to participate in action sports. For example, female college students had higher motivation than male students regarding levels of achievement, miscellaneous reasons, skills development, friendships and fun.

Although this study provided empirical results of Generation Y's different perception and motivation for participating in action sports, future studies should investigate:

- other demographic information in a different region (i.e., western region of the USA)

- Generation Y's television viewership of action sports events

- Generation Y's purchasing and consuming behaviours for sponsoring products in action sports events

- $\quad$ prediction of the next generation's preferences in action sports as spectators and participants.

\section{References}

Butler, R. (1989) 'Interest in the task and interest in peers work in competitive and noncompetitive conditions: a developmental study', Child Development, Vol. 60, pp.562-570.

Deci, E.L. and Ryan, R.M. (1985) Intrinsic Motivation and Self-determination in Human Behavior, New York: Plenum.

Deci, E.L., Betley, G., Kahle, J., Abrams, L. and Porc, J. (1981) 'When trying to win: competition and intrinsic motivation', Personality and Social Psychology Bulletin, Vol. 7, pp.79-83.

DesMarteau, K. (2004) 'Action sports success: total immersion required', Apparel Magazine, June, Vol. 45, No. 10, pp.12-13.

Doka, K., Schwarz, E.E. and Schwarz, C. (1990) 'Risky business: observations on the nature of death in hazardous sports', OMEGA: The Journal of Death and Dying, Vol. 21, pp.215-223.

Dwyer, J.J.M. (1992) 'Informal structure of participation motivation questionnaire completed by undergraduates', Psychological Reports, Vol. 70, pp.283-290.

Gill, D.L. (2000) Psychological Dynamics of Sport and Exercise, 2nd ed., Champaign, IL: Human Kinetics.

Gill, D.L., Gross, J.B. and Huddleston, S. (1983) 'Participation motivation in youth sports', International Journal of Sport Psychology, Vol. 14, pp.1-14.

Gould, D., Feltz, D. and Weiss, M.R. (1985) 'Motives for participating in competitive youth swimming', International Journal of Sport Psychology, Vol. 6, pp.126-140. 
Hu, L-T. and Bentler, P.M. (1999) 'Cutoff criteria for fit indexes in covariance structure analysis: conventional criteria versus new alternatives', Structural Equation Modeling, Vol. 6, pp.1-55.

Kaufman, M. (2001) 'Board sports stoke equipment, apparel sales', SportsBusiness Journal, 20-26 August, Vol. 4, No. 18, p.24.

Kim, K. (2002) AMOS 4.0, Seoul, Korea: Data Solution.

Klint, K.A. and Weiss, M.R. (1986) 'Dropping in and dropping out: participation motives of current and former youth gymnasts', Canadian Journal of Applied Sport Sciences, Vol. 11, pp.106-114.

Klint, K.A. and Weiss, M.R. (1987) 'Perceived competence and motives for participating in youth sports: a test of Harter's competence motivation theory', Journal of Sport Psychology, Vol. 9 , pp.55-65.

Lepper, M.R. and Hodell, M. (1989) 'Intrinsic motivation in the classroom', in C. Ames and R. Ames (Eds.) Research on Motivation in Education: Vol. 3. Goals and Cognitions, New York: Academic Press, pp.73-105.

Maffesoli, M. (1995) The Time of the Tribes: The Decline of Individualism in Mass Societies, London: Sage.

Participation Rates Slide (2000) Sporting Goods Business, ,5 June, Vol. 33, No. 9, p.10.

Passer, M.W. (1988) 'Determinants and consequences of children's competitive stress', in F. Smoll, R. Magill and M. Ash (Eds.) Children in Sport, Champaign, IL: Human Kinetics, 3rd ed., pp.203-228.

Petrecca, L. (2000) 'Going to extremes; excess of X's: marketers are testing the limits of hot teen buzzword', Advertising Age, 24 July, Vol. 71, p.16.

Recours, R.A., Souville, M. and Griffet, J. (2004) 'Expressed motives for informal and club/association-based sports participation', Journal of Leisure Research, Vol. 36, No. 1, pp.1-22.

Shoham, A., Rose, G.M. and Kahle, L.R. (1998) 'Marketing of risky sports: from intention to action', Journal of the Academy of Marketing Science, Vol. 26, No. 4, pp.307-321.

Sports Participation Trends (2003) The Journal of Physical Education, Recreation and Dance, September, Vol. 74, No. 7, p.12, http://0-web13.epnet.com.source.unco.edu/ DeliveryPrintSave.asp?tb=1\&_ug=sid+582837 (retrieved 9 October 2004).

Vallerand, R.J., Gauvin, L.I. and Halliwell, W.R. (1986) 'Negative effects of competition on children's intrinsic motivation', Journal of Social Psychology, Vol. 126, pp.365-372.

Vlachopoulos, S.P., Karageorghis, C.I. and Terry, P.C. (2000) 'Motivation profiles in sport: a self-determination theory perspective', Research Quarterly for Exercise and Sport, Vol. 71, No. 4, pp.387-398.

Wankel, L.M. and Kreisel, P.J. (1985) 'Factors underlying enjoyment of youth sports: sport and age group comparisons', Journal of Sport Psychology, Vol. 7, pp.51-64.

Weiss, M.R. and Chaumeton, N. (1992) 'Motivational orientations in sport', in T. Horn (Ed.) Advances in Sport Psychology, Champaign, IL: Human Kinetics, pp.61-99.

Yin, S. (2001) 'Going to extremes', American Demographics, June, Vol. 23, No. 6, p.26. 